\title{
Cholesterol lowering in pigs through enhanced bacterial bile salt hydrolase activity
}

\author{
I. De Smet, P. De Boever and W. Verstraete* \\ Laboratory of Microbial Ecology, Faculty of Agricultural and Applied Biological Sciences, University Gent, \\ Coupure Links 653, B-9000 Gent, Belgium
}

(Received 28 May 1996 - Revised 4 July 1997 - Accepted 21 July 1997)

\begin{abstract}
The effect of feeding live Lactobacillus reuteri cells containing active bile salt hydrolase (BSH) on plasma cholesterol levels was studied in pigs. During an experiment lasting 13 weeks, twenty pigs were fed on a high-fat, high-cholesterol, low-fibre diet for the first 10 weeks, and a regular pig diet for the last 3 weeks. One group of animals received, twice daily, 11.25 (SD 0.16$) \log _{10}$ colony forming units of the potential probiotic bacteria for 4 weeks (from week 3 until week 7 ). From week 8 onwards, the treated group was again fed on the same diet as the control group without additions. The total faecal Lactobacillus counts were only significantly higher in the treated pigs during the first 2 weeks of $L$. reuteri feeding. Based on limited data, it was suggested that the administered Lactobacillus species had caused a temporary shift within the indigenous Lactobacillus population rather than permanently colonizing the intestinal tract. The probiotic feeding brought about significant lowering $(P \leq 0.05)$ of total and LDL-cholesterol concentrations in the treated pigs compared with the control pigs, while no change in HDLcholesterol concentration was observed. The data for faecal output of neutral sterols and bile salts were highly variable between the animals of each group, yet they indicated an increased output in the treated pigs. Although the blood cholesterol levels went up in both groups during the 3 weeks following the Lactobacillus administration period, significantly lower serum total and LDL-cholesterol levels were observed in the treated pigs. During the final 3 weeks of normalization to the regular diet, cholesterol concentrations significantly decreased in both animal groups and the differences in total and LDL-cholesterol concentrations between the groups largely disappeared.
\end{abstract}

Lactobacilli: Bile salts: Serum cholesterol: Pig

Blood cholesterol concentration is largely determined by dietary fat and cholesterol intake. Fat- and cholesterol-rich Western diets are also often deficient in fibre, which is reported to promote more rapid bowel transit and increased faecal excretion of fat, cholesterol and bile salt derivatives (Costa et al. 1994). Results from several epidemiological and clinical studies indicate a positive correlation between elevated total serum cholesterol levels, mainly reflecting the LDL-cholesterol, and the development of atherosclerosis and related cardiovascular diseases.

With the emergence of a more health conscious society, the role of probiotic food products in human health has gained much attention from both consumers and producers. Lactic acid bacteria have often been suggested to exert beneficial effects on human health. As reviewed by De Smet et al. (1994), lactic acid bacteria with the active bile salt hydrolase (BSH), or cultured products containing them, are suggested to bring about a lowering of serum cholesterol levels through an interaction with the host's bile salt metabolism. The proposed mechanism of cholesterol lowering is comparable with that of a cholestyramine treatment which, like other bile salt sequestrants such as colestipol, binds bile salts and prevents them from being reabsorbed (Grundy, 1972; Suckling et al. 1991). Thus, a decreased amount of bile salts would return to the liver, resulting in a loss of feedback inhibition of bile salt synthesis and an increased conversion of cholesterol to bile salts. The ingestion of lactic acid bacteria containing active

\footnotetext{
Abbreviations: BSH, bile salt hydrolase; CFU, colony-forming units; EHC, enterohepatic cycle; FER, feed efficiency ratio; HCA, hyocholic acid; HDC.A, hyodeoxycholic acid; LCA, lithocholic acid; RLF, reconstituted lactobacilli-free.

*Corresponding author: Professor W. Verstraete, fax +32 (0)9 26462 48, email Willy.Verstraete@rug.ac.be
} 
BSH results in higher proportions of deconjugated free bile salts, which are less water-soluble and are more easily excreted via the faeces (De Smet et al. 1994). This drain on the bile salt pool might be regarded as a 'biological' alternative to common medical or surgical interventions to treat hypercholesterolaemia (De Smet et al. 1994).

Based on these dietary elements, a pig experiment was designed to assess the impact of ingestion of BSH-active lactobacilli on serum cholesterol levels. It was suggested that this might only be properly studied in a population that deviates from the 'normal, healthy' status because of strong homeostatic regulation of cholesterol metabolism in normal conditions which is also seen in human subjects (De Smet et al. 1994). Therefore, hypercholesterolaemia was induced in the animals by feeding them on a diet rich in cholesterol and saturated fat and low in fibre content. The contents of fat $(30 \%$ total energy intake) and cholesterol $(2-4 \mathrm{~g} / \mathrm{kg})$ in the 'Western type' diet were in line with those applied in other pig experiments investigating features related to blood and/or faecal sterol levels (Mott et al. 1973; Kim et al. 1980; Juste et al. 1983; Danielson et al. 1989; Costa et al. 1994).

The main objective of the present study was to validate the hypothesis that enhancing BSH activity; through feeding the highly BSH-active $L$. reuteri strain, might lower serum cholesterol levels in pigs (De Smet et al. 1994). The study also aimed to evaluate the effect of probiotic feeding on faecal variables such as $\mathrm{pH}, \mathrm{DM}$ content and bacteriology, and on the overall growth performance of the pigs.

\section{Materials and methods}

\section{Animals}

Twenty Seghers hybrid (sow) $\times$ Piétrain (boar) pigs (ten females and ten castrated males) of about $30 \mathrm{~kg}$ live weight, aged 10 weeks, were divided into two experimental groups i.e. the control pigs and the pigs to be treated with the probiotic. The pigs were allocated to one of the groups in such a way that both groups showed equal distributions of the sexes, and equal initial weights and cholesterol levels. The animals were housed in separate cages in a temperature-controlled room (22 (SD 1) $)^{\circ}$ ) at the Rijksstation voor Veevoeding in Melle-Gontrode (Belgium). The pigs were inspected daily for any evidence of diarrhoea, constipation or other illnesses or anomalies, and were weighed at the beginning and end of each experimental period. An extra weighing was done in the middle of the probiotic feeding period.

\section{Experimental outline and diets}

The experiment lasted 13 weeks (Table 1). During the first 5 weeks, all pigs received a 'Western type' high-fat, lowfibre diet, which contained $2 \mathrm{~g}$ cholesterol $/ \mathrm{kg}$ (Tables 2 and 3 ). During the following 5 weeks, the animals were fed on the same hypercholesterolaemic diet but the cholesterol content was doubled $(4 \mathrm{~g} / \mathrm{kg})$. This was done because the serum cholesterol levels did not increase sufficiently during the first 5 weeks. During the period from week 4 to week 7 , the $L$. reuteri-treated group received the probiotic strain at both morning and evening feeds. During the last 3 weeks, all animals received a regular diet obtained from Valora (Ingelmunster, Belgium) without cholesterol addition (Table 3).

\section{Probiotic strain and preparation of the probiotic feed supplement}

The Lactobacillus strain used was isolated from fresh pig faecal material on Rogosa agar plates (Oxoid; Unipath, Gent, Belgium). The strain was identified as an $L$. reuteri strain by SDS-PAGE analysis. Its BSH activities towards glycodeoxycholic acid, taurodeoxycholic acid, glycochenodeoxycholic acid and taurochenodeoxycholic acid, determined as described earlier (De Smet et al. 1994), were 1480, 1060, 715 and $538 \mathrm{nmol}$ deconjugated bile salts formed $/ 10 \log _{10}$ colony-forming units (CFU) per min. The strain was incubated for $36 \mathrm{~h}$ at $37^{\circ}$ in MRS broth (Difco; Bio Trading, Bierbeek, Belgium) supplemented with $1.0 \mathrm{~g}$ $\mathrm{CaCO}_{3} / \mathrm{l}$. The fermentations were carried out in a Multigen fermentor model F-2000 (New Brunswick Scientific, Wezembeek-Oppem, Belgium) on a 25 litre scale without aeration and with continuous agitation at $200 \mathrm{rev} . / \mathrm{min}$. The $\mathrm{pH}$ was not controlled during the fermentation. The final fermentation cultures were centrifuged at $17000 \mathrm{rev} . / \mathrm{min}$ at $4^{\circ}$ (CEPA, Carl Padberg, Germany). The pellet was harvested and resuspended in spent medium supernatant fraction to obtain a 50 -fold concentration of the original fermentation volume. This concentrate was subsequently mixed in equal amounts with a cold solution of glycerol and non-fat dry milk $(200 \mathrm{~g} / \mathrm{l})(30: 70, \mathrm{v} / \mathrm{v})$ and stored at $-70^{\circ}$ in appropriate portions. Before feeding, the probiotic supplements were thawed at room temperature and added to the water to be mixed with the feed. Viable cell counts and BSH activity of the stored cultures were checked regularly. A dose of 11.25 (SD $0 \cdot 16$ ) $\log _{10} L$. reuteri cells was added to each morning and afternoon feed of the treated pigs during period 2 (Table 1 ).

Table 1. Experimental schedule

\begin{tabular}{|c|c|c|c|}
\hline Period 1 & Period 2* & Period 3 & Period 4 \\
\hline $\begin{array}{l}3 \text { weeks acclimatization } \\
\text { 'Western type' diet }+2 \mathrm{~g} \text { cholesterol } / \mathrm{kg}\end{array}$ & $\begin{array}{l}4 \text { weeks administration of } L \text {. reuteri } \\
\text { First } 2 \text { weeks: 'Western type' diet } \\
\quad+2 \mathrm{~g} \text { cholesterol } / \mathrm{kg} \\
\text { Last } 2 \text { weeks: 'Western type' diet } \\
\quad+4 \mathrm{~g} \text { cholesterol } / \mathrm{kg}\end{array}$ & $\begin{array}{l}3 \text { weeks post-treatment follow-up } \\
\text { 'Western type' diet } \\
+4 \mathrm{~g} \text { cholesterol } / \mathrm{kg}\end{array}$ & $\begin{array}{l}3 \text { weeks normalization } \\
\text { Regular pig diet }\end{array}$ \\
\hline
\end{tabular}

*No Lactobacillus additions to the control pigs. 
Table 2. Composition of the 'Western type' diet

\begin{tabular}{|c|c|}
\hline ingredient & $\mathrm{g} / \mathrm{kg}$ diet \\
\hline Ground maize & 354.5 \\
\hline Soyabean meal & 303.4 \\
\hline Wheat meal & 200.0 \\
\hline Tallow & 100.0 \\
\hline Dicalcium phosphate & $22 \cdot 3$ \\
\hline Vitamin and mineral premix & $10 \cdot 0$ \\
\hline lodized salt & 5.0 \\
\hline Limestone & 4.5 \\
\hline DL-Methionine & 0.3 \\
\hline Cholesterol $\dagger$ & 2.0 or 4.0 \\
\hline \multicolumn{2}{|c|}{$\begin{array}{l}\text { "The vitamin and trace element mix supplied }(\mathrm{mg} / \mathrm{kg} \text { diet): retinol } 3.6 \\
\text { cholecalciferol } 0.05 \text {, thiamin } 0.5 \text {, ergocalciferol } 3.2 \text {, niacin } 10 \text {, nicotinamide } \\
16 \text {, choline chloride } 200 \text {, tocopherols } 25 \text {, menadione } 0.5 \text {, pyridoxine } 2 \\
\text { pteroylglutamic acid } 0.05, \text { biotin } 0.06 \text {, cyanocobalamin } 0.014 \text {, Mn } 40 \text {, iodine } \\
3, \mathrm{Co} 1, \mathrm{Zn} 95, \mathrm{Mg} 50, \mathrm{Se} 0.35, \mathrm{Cu} 25 \text {, Fe } 140 \text {, butylated hydroxytoluene } 5 \\
\text { †For details, see Table } 1 \text {. }\end{array}$} \\
\hline
\end{tabular}

Table 3. Composition $(\mathrm{g} / \mathrm{kg})$ of the high-fat, high-cholesterol, lowfibre 'Western-type' diet and the regular pig diet

\begin{tabular}{lcc}
\hline Component* & 'Western-type' diet & Regular pig diet \\
\hline Carbohydrate & 290 & 330 \\
Protein & 191.9 & 160.3 \\
Fibre & 24.3 & 52.3 \\
Fat & 124.0 & 35.1 \\
Cholesterol† & 2.0 or 4.0 & - \\
Minerals & 59.6 & 60.5 \\
\hline
\end{tabular}

"Net energy contents of the 'Western-type' diet and the regular pig diet were 11.4 and $9.1 \mathrm{MJ} / \mathrm{kg}$ respectively.

+See Table 1.

\section{Acclimatization of the pigs, feeding and ration-setting}

At the start of the experiment, the animals were acclimatized to the hypercholesterolaemic diet for 3 weeks, during which they were fed twice daily (feed-water, $1.0: 1.5)$ at 08.00 and 16.00 hours. The daily feed intake of the pigs was carefully controlled because, first, blood cholesterol levels are very sensitive to the amount of feed consumed, and second, because the strain was mixed with the feed. Therefore, the amount of feed, given in two equal meals, was restricted to assure complete intake. Feed consumption was measured daily and the ration was adjusted weekly by calculating the feed efficiency ratio (FER), i.e. feed uptake : growth (g/d). On incomplete feed intake, rations were adjusted downwards to minimize interindividual differences in feed intake. The pigs had free access to drinking water.

\section{Blood sampling and cholesterol analysis}

Blood samples (about $10 \mathrm{ml}$ ) were taken by venepuncture at the beginning and end of each experimental period, including an extra sampling after 2 weeks of $L$. reuteri dosage. The samples were taken after an overnight fast before the 08.00 hours feeding. Serum was prepared and immediately analysed for total cholesterol (Allain et al. 1974), HDL-cholesterol (Warnick et al. 1982) and triacylglycerols (Fossati \& Prencipe, 1982). LDL-choles- terol was calculated from the difference between total and HDL-cholesterol and triacylglycerols (Friedewald et al. 1972).

\section{Faecal sampling and analysis}

Fresh faecal material (50-100g wet weight) was collected weekly or fortnightly for microbiological analysis, $\mathrm{pH}$ and DM determination. The faeces were transported in a cool box and processed within $1 \mathrm{~h}$ after sampling. The viable concentrations ( $\log _{10} \mathrm{CFU} / \mathrm{g}$ faeces) of total lactobacilli, enterobacteriaceae and faecal streptococci were determined on Rogosa agar (Oxoid), Violet Red Bile Glucose agar (Oxoid) and Slanetz and Bartley agar (Taylor \& Burman, 1964) respectively. At weeks 10 and 12, a qualitative screening for tauroconjugate hydrolytic lactobacilli was performed by the plate assay of Dashkevicz \& Feighner (1989).

The $\mathrm{pH}$ of the faecal samples was determined after $1 \mathrm{~h}$ homogenization of $5 \mathrm{~g}$ faeces in $50 \mathrm{ml}$ distilled water. DM was determined after $24 \mathrm{~h}$ drying at $110^{\circ}$. Portions of the samples were frozen at $-20^{\circ}$ for analysis of total bile salt and neutral sterol content.

Total faecal bile salt concentrations were determined after methanol extraction by the colorimetric assay of Mashige et al. (1981) using the bile salts fully enzyrnic colour Merckotest ${ }^{\circledR}$ kit (Merck, Darmstadt, Germany). The principle of the test is based on the conversion of $3 \alpha-$ hydroxy bile salts to the corresponding 3-keto derivatives in the presence of $\mathrm{NAD}^{+}$and with the aid of $3 \alpha-$ hydroxysteroid dehydrogenase ( $E C$ 1.1.1.53). The NAD formed reacts with nitrotetrazolium blue under the catalytic influence of diaphorase to give a blue formazan derivative, which can be quantified by measuring the absorbance. Faecal matter $(1 \mathrm{~g})$ was dissolved in $40 \mathrm{ml}$ methanol. After $4 \mathrm{~min}$ sonication and $1 \mathrm{~h}$ shaking, the mixtures were centrifuged $(10000 \mathrm{~g}, 10 \mathrm{~min})$ and $100 \mu \mathrm{l}$ of the supernatant fraction was used to determine the bile salt content. The faecal bile salt and neutral sterol profiles were analysed by GC according to the method of Lapré et al. (1993). Briefly, dried samples were pulverized and pooled. Pooled samples were made of randomly chosen individual samples of each group. In addition, a number of samples were analysed individually to establish interindividual variances within one group. The pulverized faecal samples were hydrolysed in methanol and $\mathrm{NaOH}$ at $80^{\circ}$. Neutral sterols were extracted with hexane, whereas bile salts were extracted with ether after acidification of the samples with $\mathrm{HCl}$. Subsequently, the extracts were methylated and silylated, evaporated and resuspended in hexane before GC analysis.

\section{Statistical analysis}

Results were analysed by one-way ANOVA. When statistically significant differences were found, mean values of treatments were compared by Student's $t$ test. 


\section{Results}

Animals

Although some pigs showed slightly watery faeces during the first $2 \mathrm{~d}$ of acclimatization to the high-fat-highcholesterol diet, and some pigs refused part of their diets during the first days after the shift from the high-fat-highcholesterol porridge feeding to the regular pig diet, the animals generally adapted well to the experimental conditions. One control pig showed an aberrant high FER during the normalization period. This was of temporary concern and not related to the probiotic feeding or the cholesterol rich diet. The high FER was probably due to the sudden switch to the normal diet. The pigs treated with the $L$. reuteri supplement did not develop illnesses or adverse effects compared with the control animals, and no significant differences in body weight were observed between the two animal groups throughout the experiment (Tables 4 and 5). During week 10, one of the control pigs died for an unknown reason the day after the weighing.

\section{Blood cholesterol and triacylglycerols}

Fig. 1 gives the results of the total, LDL- and HDLcholesterol determinations. After 2 weeks of $L$. reuteri

Table 4. Mean body weights of the control pigs (CP; $n$ 10) and treated pigs (TP; $n$ 10)

\begin{tabular}{lccccc}
\hline & \multicolumn{4}{c}{ Body weight $(\mathrm{kg})$} \\
\cline { 2 - 5 } & \multicolumn{2}{c}{ CP } & & \multicolumn{2}{c}{ TP } \\
\cline { 2 - 5 } Experimental period* & Mean & SD & & Mean & SD \\
\hline Week 0 & 28.95 & 0.67 & 28.95 & 0.62 \\
Week 3 & 42.90 & 1.09 & 43.10 & 0.65 \\
Week 5 & 54.30 & 1.20 & 54.20 & 0.91 \\
Week 7 & 65.75 & 1.36 & 66.10 & 1.09 \\
Week 10 & 83.30 & 1.67 & 83.30 & 1.24 \\
Week 13† & 95.00 & 2.45 & 96.45 & 1.44 \\
\hline
\end{tabular}

*See Table 1.

tn 9 for CP. feeding, the total and LDL-cholesterol levels in the treated pigs were reduced by 11 and $26 \%$ respectively, compared with the control animals $(P \leq 0.05)$, while after 4 weeks these reductions were 15 and $24 \%(P \leq 0.05)$ respectively (Fig. $1(\mathrm{a}, \mathrm{b})$ ). In the 3 weeks of post-treatment follow-up, the treated pigs showed $18 \%$ lower total cholesterol concentrations $(P \leq 0.05)$ and $34 \%$ lower LDL-cholesterol concentrations $(P \leq 0.01)$ (Fig. 1(a,b)). This could have been due either to a temporary shift towards a more BSHactive Lactobacillus population, or to the fact that serum cholesterol levels change only slowly in response to a highfat-high-cholesterol diet. As it had taken 10 weeks for the total cholesterol levels in the control pigs to rise from 2.46 to about $3.44 \mathrm{mmol} / \mathrm{l}$, it is rather doubtful that the total cholesterol level of the treated pigs could increase to that of the control pigs in a 3 -week period.

Compared with the control pigs, the total and LDLcholesterol levels in the treated pigs were lower during the 4 weeks of probiotic feeding. During the subsequent posttreatment follow-up period, the total and LDL-cholesterol concentrations in the treated pigs increased, but the levels were still significantly lower than the values measured in the control pigs. HDL-cholesterol levels were not significantly altered on $L$. reuteri feeding (Fig. 1(c)).

In the control pigs, a gradual increase of the total and LDL-cholesterol concentrations was observed during the 10 weeks of high-fat-high-cholesterol feeding (Fig. 1(a,b)), while no consistent changes were found for the HDLcholesterol levels (Fig. 1(c)). The increases in total and LDL-cholesterol levels in the control pigs at week 10 compared with week 3 were about $25 \%$ and $60 \%$ respectively (Fig. 1(a,b)). When comparing the total cholesterol concentration in the treated pigs during the treatment period, with the total cholesterol concentration at week 3, an average lowering of approximately $7 \%$ $(P>0.1)$ was observed. At week 10 the total cholesterol concentration in the $L$. reuteri-treated pigs was about $5 \%$ $(P>0.1)$ higher than at the start of the probiotic feeding at week 3, mainly due to an increase in the HDL-cholesterol concentration. When comparing the LDL-cholesterol concentration in the $L$. reuteri-treated pigs during the treatment

Table 5. Average growth, feed uptake and feed efficiency ratio (FER) of control pigs (CP; $n 10)$ and pigs treated with live Lactobacillus reuteri cells twice daily from week 3 to week 7 (TP; $n$ 10) ${ }^{\star}$

(Mean values and standard deviations)

\begin{tabular}{|c|c|c|c|c|c|c|c|c|c|c|}
\hline \multirow[t]{2}{*}{ Experimental period... } & \multicolumn{2}{|c|}{ Week $0-3$} & \multicolumn{2}{|c|}{ Week 3-5 } & \multicolumn{2}{|c|}{ Week 5-7 } & \multicolumn{2}{|c|}{ Week $7-10$} & \multicolumn{2}{|c|}{ Week 10-13: } \\
\hline & Mean & SD & Mean & SD & Mean & SD & Mean & SD & Mean & SD \\
\hline \multicolumn{11}{|l|}{ Growth $(\mathrm{g} / \mathrm{d})$} \\
\hline $\mathrm{CP}$ & 664 & 28 & 814 & 39 & 818 & 33 & 835 & 36 & 659 & 99 \\
\hline TP & 673 & 19 & 793 & 35 & 850 & 38 & 819 & 16 & 786 & 83 \\
\hline \multicolumn{11}{|l|}{ Feed uptake $(\mathrm{g} / \mathrm{d})$} \\
\hline $\mathrm{CP}$ & 1293 & 27 & 1744 & 18 & 1814 & 86 & 1896 & 7 & 2239 & 202 \\
\hline TP & 1195 & 118 & 1713 & 33 & 1841 & 46 & 1867 & 18 & 2128 & 119 \\
\hline \multicolumn{11}{|l|}{ FER $\dagger$} \\
\hline $\mathrm{CP}$ & 2.08 & 0.08 & 2.19 & 0.11 & $2 \cdot 22$ & 0.09 & $2 \cdot 30$ & 0.10 & $3.19 \S$ & 0.22 \\
\hline TP & 2.06 & 0.06 & 2.19 & 0.08 & 2.20 & 0.10 & 2.29 & 0.06 & 2.91 & 0.25 \\
\hline
\end{tabular}

"For details of diets and procedures, see Tables 1-3 and pp. 186-187.

† Feed uptake/growth

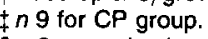

$\S n$ 8; one pig showed a FER of 24.1 and was omitted (otherwise FER would be 5.60 (SD 2.32)). 

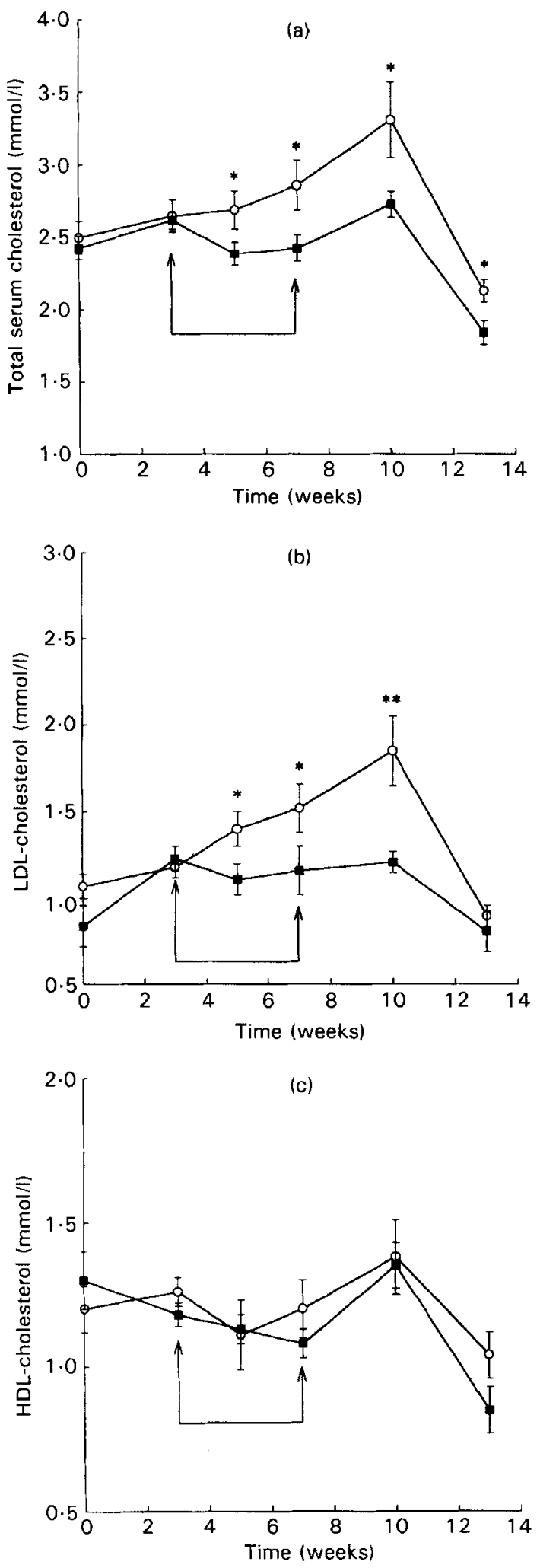

Fig. 1. (a) Total serum cholesterol, (b) LDL-cholesterol and (c) HDLcholesterol levels $(\mathrm{mmol} / \mathrm{l})$ in control pigs $(O)$ and pigs treated with live Lactobacillus reuteri cells twice daily from week 3 to week 7 (ם). Values are means for ten pigs with standard deviations indicated by vertical bars, except for week 13 control values where $n 9 .(\uparrow)$, Probiotic feeding period. Mean values were significantly different for the two groups: ${ }^{\star} P \leq 0.05,{ }^{\star \star} P \leq 0.01$. period, with the LDL-cholesterol concentration at week 3, also an average lowering of approximately $7 \%(P>0.1)$ was observed. The LDL-cholesterol levels measured in the treated pigs at week 10 were significantly $(P \leq 0.01)$ different from levels measured in the same pigs at week 5 . The observed lowering at week 5 can be explained by the addition of $L$. reuteri together with the cholesterol-rich $(2 \mathrm{~g} / \mathrm{kg})$ diet. At week 5 the cholesterol amount was doubled $(4 \mathrm{~g} / \mathrm{kg})$ and the LDL-cholesterol levels slightly increased in the treated pigs, while they increased more in the control pigs. Therefore, it is believed that the effects brought about by the supplemented strain could not fully counterbalance the effect of doubling the cholesterol concentration in the diet and hence led to an increase of the LDL-cholesterol concentration. The observed increase of total and LDLcholesterol levels of the treated pigs between week 7 and week 10 was however clearly less than the increase of the levels in the control pigs. During the last 3 weeks a commercial pig diet without cholesterol supplementation was fed, causing the cholesterol levels in both experimental groups to decrease even below the levels at the onset of the experiment (Fig. 1). At that time, LDL-cholesterol levels were no longer significantly different between the two groups (Fig. 1(b)), while the total serum cholesterol concentration in the treated pigs was still significantly lower $(P \leq 0.05$; Fig. 1(a)), mainly due to the lower HDL concentrations $(P \leq 0.10)$ in these animals (Fig. 1(c)).

The triacylglycerol concentrations did not differ significantly between the control and treated pigs throughout the experiment. The initial triacylglycerol levels for the control and treated pigs were respectively 0.56 (SD 0.05) and 0.53 (SD $0.06) \mathrm{mmol} / \mathrm{l}$. At the start and end of the probiotic feeding these levels were for the control pigs 0.58 (SD 0.06) and 0.44 (SD 0.07) $\mathrm{mmol} / \mathrm{l}$, and for the treated pigs 0.48 (SD 0.04) and 0.46 (SD 0.04) mmol/1. After 3 weeks post-treatment followup and the final 3 weeks of normalization to the regular pig diet, the triacylglycerol concentrations in the control pigs were 0.39 (SD 0.03) and 0.44 (SD 0.05$) \mathrm{mmol} / 1$ respectively, whereas for the treated pigs they were 0.44 (SD 0.03) and 0.43 (SD 0.05 ) $\mathrm{mmol} / \mathrm{l}$ respectively.

\section{Faecal excretion of bile salts and neutral sterols}

The data on total faecal bile salt excretion determined colorimetrically, reveal that the total bile salt output increased in both animal groups during the course of the 'Western type' diet feeding (Fig. 2). A $25 \%$ higher excretion $(P \leq 0.05)$ was observed in the treated group compared with the control group after 1 week of $L$. reuteri ingestion. This higher output lasted until the end of the Lactobacillus treatment, and it decreased again to the level of the control animals after the treatment was stopped. The faecal bile salt excretions in the control pigs however also increased due to the high-fat and high-cholesterol feeding. Compared with the initial value (week 0, Fig. 2), the faecal output was increased by $13 \%(P \leq 0 \cdot 10)$ at week $6,26 \%$ at week $8(P \leq 0 \cdot 10)$, and $25 \%$ at week $10(P \leq 0.01)$.

A detailed faecal bile salt profile was obtained by GC analysis, and the data on the three major compounds, i.e. lithocholic acid (LCA), hyodeoxycholic acid (HDCA) and 


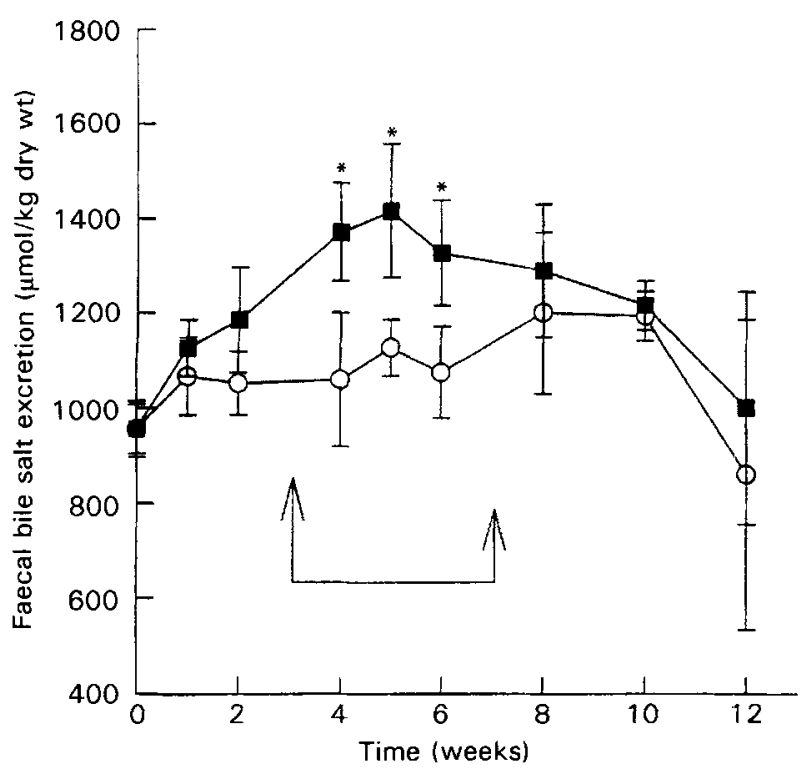

Fig. 2. Total faecal bile salt excretion ( $\mu \mathrm{mol} / \mathrm{kg}$ dry faeces) of control pigs $(O)$ and pigs treated with live Lactobacillus reuteri cells twice daily from week 3 to week $7(\square)$. Analyses were performed in duplicate. Values are means for ten pigs with standard deviations indicated by vertical bars, except for week 12 control values where $n$ 9. ( $\uparrow)$, Probiotic feeding period. Mean values were significantly different for the two groups: ${ }^{*} P \leq 0.05$.

hyocholic acid (HCA) are presented in Table 6. The concentrations of cholic, deoxycholic, chenodeoxycholic and $\alpha$-muricholic acid are not given separately in Table 6, because they were lower than $0.5 \mu \mathrm{mol} / \mathrm{g}$ dry faeces or even below the detection limit $(0 \cdot 1 \mu \mathrm{mol} / \mathrm{g}$ dry faeces $)$. The total bile salt concentrations were approximately a factor of ten higher compared with those given in Fig. 2, which may be attributed to methodological aspects such as different extraction or detection efficiencies of the respective assays. The evolution in time of the total bile salt excretion was found to be variable, and large interindividual variances were observed between the animals of one group (variances of the values in square brackets, Table 6). When evaluating the data obtained from the analysis of four individual samples (values in square brackets, Table 6), there was a trend towards higher bile salt excretions in the faeces of treated pigs. However, these results calculated from four individually analysed samples differed greatly from those of the five-sample pooling of week 6 for the same experimental group (Table 6). Hence, no unequivocal conclusions should be drawn from these pooled data. Finally, it was found that the ratio HCA : (HDCA + LCA), i.e. primary: secondary bile salts, was markedly decreased in both groups on feeding the 'Western type' diet, i.e. from 0.35 at the start of the experiment to less than 0.10 after 8 weeks high-fat-high-cholesterol feeding (Table 6). Although no major differences were observed between the two animal groups, this ratio was slightly higher (about 1.2-1.6 times) in the treated pigs during the probiotic feeding.

Table 6 also gives the faecal concentrations of cholesterol and total neutral sterols. The total neutral sterol output increased on high-fat-high-cholesterol feeding, whereas it decreased markedly at week 12 , i.e. 2 weeks after the 'Western type' diet feeding was stopped. The individual faeces samples of the treated pigs showed a significantly lower $(P \leq 0.01)$ cholesterol excretion in week 6 . The cholesterol, coprostanol and total neutral sterol outputs in the control pigs at week 12 were significantly lower $(P \leq 0.05)$ compared with the treated pigs. It could also be calculated that during the high-fat-high-cholesterol feeding the cholesterol:coprostanol ratio changed in a similar way in both groups. At the start of the experiment it

Table 6. Faecal concentrations ( $\mu \mathrm{mol} / \mathrm{g}$ dry faeces) of neutral sterols and bile salts in control pigs $(\mathrm{CP} ; n$ 10) and pigs treated with live Lactobacillus reuteri cells twice daily from week 3 to week 7 (TP; $n$ 10) $\dagger$

(Values are for pooled samples of five randomly chosen faecal samples from each group)

\begin{tabular}{|c|c|c|c|c|c|c|c|c|}
\hline Experimental period & & Cholesterol & Coprostanol & Total neutral sterols & LCA & HDCA & $\mathrm{HCA}$ & Total bile salts \| \\
\hline \multirow[t]{2}{*}{ Week 0} & $\mathrm{CP}$ & 9.1 & 24.9 & 36.0 & 1.5 & 4.6 & $2 \cdot 2$ & 9.0 \\
\hline & TP & 7.4 & 20.6 & 31.5 & 1.8 & 3.5 & 2.0 & 8.1 \\
\hline \multirow[t]{2}{*}{ Week 2} & $\mathrm{CP}$ & 8.8 & $25 \cdot 1$ & 36.4 & 1.6 & 3.8 & 1.1 & 7.0 \\
\hline & TP & 7.5 & $24 \cdot 3$ & 33.8 & 1.9 & 3.9 & 0.9 & 7.5 \\
\hline \multirow[t]{2}{*}{ Week 4} & $C P$ & 8.2 & 21.7 & 31.5 & 3.6 & 7.0 & 1.2 & 12.9 \\
\hline & $\mathrm{TP}$ & 9.1 & 21.9 & 33.1 & $2 \cdot 3$ & 2.9 & 0.7 & 6.8 \\
\hline \multirow[t]{3}{*}{ Week 6} & $\mathrm{CP}$ & 11.3 & $40 \cdot 0$ & 54.6 & 2.4 & 3.4 & 0.8 & 7.5 \\
\hline & & {$\left[10.0^{\star \star}(S D 0.7)\right] \S$} & [39.2 (SD 4.9)] & [52.5 (SD 5.2)] & {$[2.5($ SD 0.7)] } & [4.5 (SD 2.2)] & {$[0.8(S D 0.2)]$} & {$[8.8(S D 3.6)]$} \\
\hline & $\mathrm{TP}$ & $\begin{array}{c}9.2 \\
{[6.9(S D 0.5)]}\end{array}$ & $\begin{array}{c}40.9 \\
{[43.0(\text { SD } 4.9)]}\end{array}$ & $\begin{array}{c}52.8 \\
{[54.2 \text { (SD 5.1)] }}\end{array}$ & $\begin{array}{c}2.6 \\
{[2.7 \text { (SD 0.7)] }}\end{array}$ & $\begin{array}{c}1.3 \\
{[6.1(\operatorname{SD~} 2.0)]}\end{array}$ & $\begin{array}{c}0.7 \\
{[1.2(\text { SD } 0.3)]}\end{array}$ & $\begin{array}{c}5.5 \\
{[11.2 \text { (SD 3.1)] }}\end{array}$ \\
\hline \multirow[t]{2}{*}{ Week 8} & $\mathrm{CP}$ & 9.4 & $40 \cdot 2$ & 51.4 & $7 \cdot 1$ & $8 \cdot 1$ & 1.2 & 17.9 \\
\hline & TP & 9.8 & 39.9 & 51.4 & 3.8 & 6.1 & 0.9 & 12.5 \\
\hline \multirow[t]{2}{*}{ Week 129} & $\mathrm{CP}$ & $2.4^{\star}$ (SE 0.2) & $4.2^{*}$ (SE 0.2) & $6.8^{*}$ (SE 0.4) & 2.4 & 9.0 & 1.5 & 13.9 \\
\hline & $\mathrm{TP}$ & 3.1 (SE 0.2) & 7.6 (SE 0.7) & 10.9 (SE 0.9) & $3 \cdot 1$ & 9.1 & 1.6 & $15 \cdot 1$ \\
\hline
\end{tabular}

LCA, lithocholic acid; HDCA, hyodeoxycholic acid; HCA, hyocholic acid.

Mean values were significantly different from those for TP: ${ }^{*} P \leq 0.05,{ }^{* *} P \leq 0.01$

†For details of diets and procedures, see Tables 1-3 and pp. 186-187.

$\$$ Sum of cholesterol, coprostanol and epicoprostanol.

$\$$ Values for week 6 in square brackets are means and standard deviations for four individual samples from the remaining faecal samples not included in the pooling

"I Sum of cholic, deoxycholic, chenodeoxycholic, $\alpha$-muricholic acids, LCA, HDCA and HDA.

II Values are means with their standard errors for duplicate analysis of pooled samples. 
was about 0.35 in both groups but by week 6 , the ratios calculated from the data of the four individual analyses were, for the control and treated pigs, lowered to 0.27 and 0.17 respectively, which were significantly different $(P \leq 0.05)$. At week 12, the cholesterol : coprostanol values had again increased to 0.57 in the control pigs and 0.40 in the treated pigs.

\section{pH and DM of the faeces}

No significant differences in $\mathrm{pH}$ and $\mathrm{DM}$ content were observed on probiotic feeding compared with the control pigs (Table 7).

Table 7. $\mathrm{pH}$ and DM content of faeces from control pigs (CP; $n$ 10) and pigs treated with live Lactobacillus reuteri cells twice daily from week 3 to week 7 (TP; $n$ 10)

(Mean values and standard deviations)

\begin{tabular}{lccccc}
\hline & & \multicolumn{2}{c}{ pH } & \multicolumn{2}{c}{ DM $(\mathrm{g} / \mathrm{kg})$} \\
\hline Experimental period & Group & Mean & SD & Mean & SD \\
\hline Week 0 & CP & 7.02 & 0.06 & 248.6 & 6.8 \\
Week 2 & TP & 7.70 & 0.10 & 256.0 & 4.1 \\
Week 5 & CP & 6.85 & 0.08 & 255.7 & 5.3 \\
Week 8 & TP & 6.85 & 0.08 & 251.5 & 6.1 \\
Week 10 & CP & 6.72 & 0.07 & 267.6 & 8.7 \\
Week 12 $\dagger$ & TP & 6.62 & 0.05 & 262.7 & 6.3 \\
& CP & 6.68 & 0.09 & 273.0 & 4.8 \\
& TP & 6.62 & 0.08 & 276.8 & 7.3 \\
& CP & 6.97 & 0.08 & 296.9 & 8.5 \\
& TP & 7.15 & 0.17 & 294.5 & 8.8 \\
& CP & 7.00 & 0.19 & 272.7 & 10.3 \\
& TP & 6.91 & 0.11 & 278.2 & 7.6 \\
\hline
\end{tabular}

"For details of diets and procedures, see Tables 1-3 and pp. 186-187. t $n 9$ for CP group.

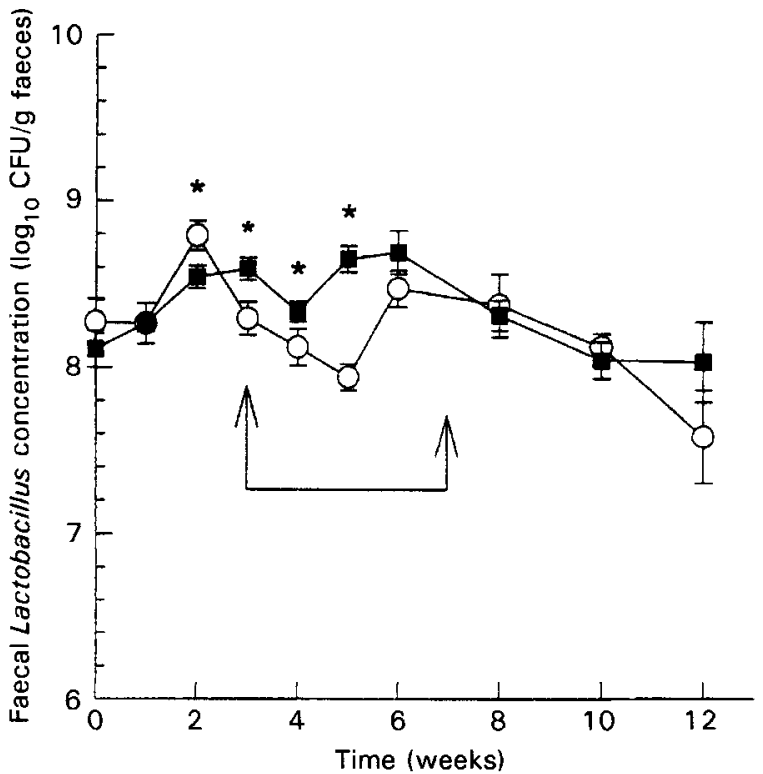

Fig. 3. Faecal Lactobacillus concentration ( $\log _{10}$ colony-forming units (CFU)/g faeces) in control pigs $(O)$ and pigs treated with live Lactobacillus reuteri cells twice daily from week 3 to week 7 ( $\square$ ). Values are means for ten pigs, with standard deviations indicated by vertical bars, except for week 12 control values where $n 9$. ( $\uparrow$, Probiotic feeding period. Mean values were significantly different for the two groups: ${ }^{\star} P \leq 0.05$.

\section{Bacteriological examination of the faeces}

Fig. 3 shows the faecal Lactobacillus counts in the control and treated pigs. The average Lactobacillus count in the control animals was significantly higher compared with the treated pigs $(P \leq 0.05)$ in week 2 , while from week 3 to week 5 the Lactobacillus counts of the treated pigs were significantly higher than those of the control pigs. However, no significant differences were observed from week 6 until the end of the experiment. The numbers of faecal streptococci and enterobacteriaceae were not significantly different between the groups, except for the concentrations of faecal streptococci in the treated pigs in week 6 , and of the enterobacteriaceae in week 8 , which were significantly lower $(P \leq 0.05)$ compared with the respective counts of the control pigs (results not shown).

Total and LDL-cholesterol levels were still significantly lower 3 weeks after the probiotic feeding was stopped despite the fact that the total numbers of lactobacilli had returned to their initial levels. This may, in part, have been a consequence of the probiotic feeding, whereby a temporary shift in the lactobacilli population occurred, through which the administered strain partly replaced the native lactobacilli and exerted a prolonged effect on the serum cholesterol level. To verify this, the numbers of BSH-active lactobacilli present in the faeces at the last two samplings, i.e. at weeks 10 and 12 , were enumerated by means of the plate assay of Dashkevicz \& Feighner (1989). Table 8 illustrates that, in week 10 , there was a trend towards a higher amount of BSH-active lactobacilli in the treated pigs $(32.45 \%)$ compared with the control pigs $(21.96 \%)$. The relative amount of BSH-active lactobacilli decreased in the treated pigs to $20.80 \%$ in week 12 $(P \leq 0 \cdot 10)$, whereas it remained approximately the same for the control pigs over that 2-week period. However, the data are too limited to fully substantiate the thesis that there was a temporary shift towards a more $\mathrm{BSH}$-active lactobacillus population in the treated pigs. Further studies, in which the variation of faecal BSH-active lactobacilli is followed throughout the whole experiment, are required.

\section{Discussion}

The main goal of the present study was to evaluate the effect of feeding the $\mathrm{BSH}$-active $L$. reuteri strain on the blood cholesterol levels of pigs in order to validate the hypothesis that enhanced intestinal BSH activity might lower blood cholesterol levels (De Smet et al. 1994). Evidence for this mechanism was sought in a combined study of blood cholesterol levels and faecal bile salt and neutral sterol content. Ratcliffe \& Luginbühl (1971) found the pig to be one of the most suitable models to study atherosclerosis, because the distribution of coronary arteries and atherosclerotic tendencies in pigs resemble those of man. Furthermore, apart from their similar digestive systems (Miller \& Ullrey, 1987), pigs and human subjects were also reported to have a similar lipoprotein metabolism and extensive apolipoprotein homology (Chapman, 1986; Black \& Davidson, 1989; Black et al. 1990).

In the present study, HDL-cholesterol concentrations were not significantly altered after 4 weeks of Lactobacillus 
Table 8. Viable counts of total and bile salt hydrolase-active $\left(\mathrm{BSH}^{+}\right)$lactobacilli $\left(\log _{10}\right.$ colony-forming units/g wet faeces) in the faeces of control pigs (CP; $n 10)$ and pigs treated with live Lactobacillus reuteri cells twice daily from week 3 to week 7 (TP; $n 10)^{*}$

(Mean values and standard deviations)

\begin{tabular}{|c|c|c|c|c|c|c|c|}
\hline \multirow[b]{2}{*}{ Sampling time } & & \multicolumn{2}{|c|}{ Total lactobacilli } & \multicolumn{2}{|c|}{$\mathrm{BSH}^{+}$lactobacilli } & \multicolumn{2}{|c|}{$\begin{array}{c}\mathrm{BSH}^{+} \text {lactobacilli } \\
\text { (\% total) }\end{array}$} \\
\hline & & Mean & SD & Mean & SD & Mean & SD \\
\hline \multirow[t]{2}{*}{ Week 10} & $\mathrm{CP}$ & 8.12 & 0.08 & 7.40 & 0.05 & 21.96 & 3.48 \\
\hline & TP & 8.04 & 0.11 & 7.55 & 0.09 & 32.45 & 7.33 \\
\hline \multirow[t]{2}{*}{ Week $12 \dagger$} & $\mathrm{CP}$ & 7.58 & 0.28 & 6.41 & 0.25 & 18.22 & 2.33 \\
\hline & TP & 8.03 & 0.24 & 7.34 & 0.26 & 20.80 & 3.33 \\
\hline
\end{tabular}

*For details of diets and procedures, see Tables $1-3$ and pp. 186-187. tn 9 for CP group.

feeding (Fig. 1(c)), whereas the total and LDL-cholesterol levels were significantly lower by 15 and $24 \%$ respectively compared with the control animals. When comparing the evolution in time of the total and LDL-cholesterol fractions, a clear cholesterol controlling effect of the $L$. reuteri cells is demonstrated. As expected, cholesterol concentrations markedly decreased in both animal groups and the differences between the groups largely disappeared during the final 3 weeks of normalization to the regular pig diet (Fig. 1). Triacylglycerol levels were not found to be significantly different between the control and treated pigs throughout the experiment. In this context, the net positive effect on plasma cholesterol obtained in the present pig experiment should be compared with the cholesterol reductions on therapeutic or surgical interruption of the enterohepatic cycle (EHC), which have been reported to be in the range of 15-30\% (Grundy, 1972; Grundy et al. 1972).

It was shown that the total faecal bile salt excretion, as determined enzymically, increased in both animal groups throughout the high-fat-high-cholesterol feeding period, whereas it decreased again on feeding the regular pig diet (Fig. 2). This finding is in agreement with the reported higher faecal excretion due to diets rich in fat and cholesterol (Aries et al. 1969; Armstrong \& Doll, 1975; van Faassen et al. 1987; Korpela et al. 1988). A significantly higher excretion was determined in the treated pigs during the probiotic addition (Fig. 2). No such consistent data were obtained by GC analysis of pooled samples (Table 6). Besides the observed increases and decreases in faecal neutral sterol output in both groups in response to the high and low dietary fat and cholesterol intakes respectively (Table 6), the interindividual differences were such that the analysis of pooled samples of five randomly chosen samples did not yield interpretable data.

Despite the discrepancies in the data on faecal bile salts of Fig. 2 and Table 6, they partly indicate changes in bile salt metabolism due to ingestion of BSH-active lactobacilli. In this regard, several reports have described the role of the indigenous bacteria in the overall bile salt metabolism (Gustafsson et al. 1977; Madsen et al. 1978; Chikai et al. 1987). These studies, performed with germ-free rats or rats in which the normal microbiota was selectively eliminated by antibiotics, demonstrated lower faecal bile salt excretions and no free bile salts in germ-free animals, due to the absence of the normal BSH-active microbiota. Mott et al. (1973) reported that when germ-free pigs developed an intestinal microbiota, microbial conversion of cholesterol to coprostanol and of primary to secondary bile salts was responsible for increased neutral sterol excretions and bile salt turnover rates and a concomitant decrease in serum cholesterol levels.

Although the impact of changes in the EHC due to bile salt and/or cholesterol metabolism on the development of atherosclerosis has been recognized, there is a medical concern about possible side-effects. According to some authors (Hylemon \& Glass, 1983; Kandell \& Bernstein, 1991) enhanced BSH activity in the gut is not desirable because dehydroxylation of primary bile salts to cocarcinogenic and co-mutagenic secondary free bile salts, which could induce colorectal cancer, can take place more easily after the initial deconjugation (Cohen et al. 1980; Owen et al. 1986; van Faassen et al. 1987; Nagengast et al. 1995). In particular the increase in faecal secondary bile salts on ingestion of BSH-active lactobacilli should, according to Marteau et al. (1995), be regarded as a potential long-term colon cancer promoting effect. It was demonstrated that the ratio primary: secondary bile salts was reduced in both experimental groups on feeding the high-fat-high-cholesterol diet. Although the ratio primary : secondary bile salts was found to be slightly higher in the treated pigs on probiotic feeding, these data were subject to large variability (Table 6). Similarly, as for bile salts, increased faecal neutral sterol excretion has been associated with an increased risk of colorectal cancer (van Faassen et al. 1987; Korpela et al. 1988). In addition, intestinal bacterial metabolism of neutral sterols has also been suggested as a risk factor, although inconsistent and conflicting results have been reported on this aspect (van Faassen et al. 1987; Korpela et al. 1988). However, our data did not allow this aspect to be assessed and this should be further investigated.

The administration of 11.25 (SD 0.16 ) $\log _{10}$ L. reuteri cells twice daily resulted in significantly higher faecal Lactobacillus counts during the first 2 weeks of Lactobacillus feeding only (Fig. 3) and no consistent changes were observed in the numbers of enterobacteriaceae and faecal streptococci (results not shown). Because the proportion of BSH-active lactobacilli among the total faecal lactobacilli decreased in the treated pigs after the $L$. reuteri addition 
was stopped (Table 8), it was presumed that the L. reuteri cells were gradually washed out and that they did not succeed in permanently colonizing the intestinal tract. This suggested temporary shift within the intestinal Lactobacillus population corroborates the finding of Wolf et al. (1995) that human subjects, who had consumed $11 \log _{10}$ L. reuteri cells daily for 3 weeks, showed no increase in total faecal lactobacilli, although they did show an increase in the relative proportion of $L$. reuteri.

The faecal pH and DM content (Table 7) did not change significantly on feeding the $L$. reuteri strain. These variables were within the normal values reported in the literature, i.e. about $25 \%$ for the DM content and between 6.5 and 7.0 for the faecal pH (Kidder \& Manners, 1978). No diarrhoea was observed in the treated pigs, although fat malabsorption and diarrhoea have been suggested as potential dangerous sideeffects of the ingestion of BSH-active lactic acid bacteria (Marteau \& Rambaud, 1993; Marteau et al. 1995). During week 10, one of the control pigs died for an unknown reason, but no illnesses or adverse effects were otherwise observed in any of the pigs. The treated animals in the present experiment showed no impairment of growth performance (Tables 4 and 5 ) and the dose of 11.25 (SD 0.16) $\log _{10}$ L. reuteri twice daily was shown to be tolerated well. This is in agreement with the report of Wolf et al. (1995) in which no significant safety or tolerance problems were observed in male subjects after several weeks consumption of a similar dose of an $L$. reuteri strain.

Agerbæk et al. (1995) demonstrated in human subjects a $10 \%$ reduction in LDL-cholesterol due to the consumption of a fermented milk containing an Enterococcus faecium strain and two Streptococcus thermophilus strains. Although the $E$. faecium strain was suggested to be responsible for the cholesterol lowering, no mechanism of action was proposed. Apart from this human study, most studies published have used small laboratory animals. Fukushima \& Nakano (1995) demonstrated a mixture of several Bacillus, Lactobacillus, Streptococcus, Saccharomyces and Candida strains to lower significantly total and LDL-cholesterol and to increase HDL-cholesterol concentrations in rats kept on a high-fat and high-cholesterol $(10 \mathrm{~g} / \mathrm{kg})$ diet. This coincided with increased faecal neutral and acidic sterol concentrations. No specific mechanism was claimed, but it was suggested that the probiotic mixture might have been effective through symbiotic relationships in the intestine, by improving the intestinal microbial balance and by promoting the binding of bile salts and the inhibition of micelle formation in the intestine (Fukushima \& Nakano, 1995). Tannock et al. (1994), who inoculated reconstituted lactobacilli-free (RLF) mice with three BSHactive Lactobacillus strains, showed an $86 \%$ increase in BSH activity, and a concomitant increase in deconjugated bile salts in the intestinal tract of these RLFL mice (i.e. RLF mice inoculated with lactobacilli) compared with the RLF mice. In a mouse experiment by Tannock \& McConnell (1994), the same mode of action as we investigated in the present pig experiment was proposed, namely cholesterol lowering through (enhanced) BSH activity of lactobacilli. After inoculating RLF mice with BSH-active Lactobacillus strains, the serum cholesterol levels of the RLFL mice were reduced by 4-5\% compared with RLF mice. No data were reported on faecal sterol output (Tannock \& McConnell, 1994). As these investigators found the cholesterol lowering to be insignificant, they concluded that lactobacilli originating from conventional mice did not influence the cholesterol balance. However, as it was not reported how many viable lactobacilli were effectively inoculated, it could be expected that a more pronounced effect might have been achieved at sufficient Lactobacillus doses. Probiotic effects on cholesterol are likely to be dose-dependent, in a similar way as medical therapies in this field. In addition, Suckling et al. (1991) demonstrated that the 'minimal effective dose' and 'doseresponse relationship' of cholestyramine treatment differed in human subjects, dogs and hamsters in the extent to which the removal of bile salts lowered cholesterol. The dosage of 11.25 (SD 0.16) $\log _{10} L$. reuteri cells in our pig experiment yielded total and LDL-cholesterol reductions in the order of $25-35 \%$ and $10-20 \%$ respectively compared with the control animals. Therefore, the reported positive relationship in pigs between increased faecal neutral sterols and bile salts and serum cholesterol lowering (Mott et al. 1973; Dupont et al. 1974; Kim et al. 1980; Scholz et al. 1985) indirectly substantiates our proposed hypothesis on the interaction between BSH activity and cholesterol. Based on these literature data, the effects on cholesterol obtained in our pig model may thus be quite promising in respect of extrapolation to the human lipid metabolism. They should nevertheless be validated in a long-term human trial, focusing on the dose-response relationship of the cholesterol-lowering effect in relation to faecal sterols, and on possible side-effects in the long run. Fermented foods containing BSH-active lactobacilli may then 'normalize' a deviating physiological condition of cholesterol metabolism, i.e. they may be preventive in the cholesterol control of people who are conscious of their unhealthy diet, but they may, on adequate dosage, also offer a valid alternative to pharmaceutical intervention in hypercholesterolaemic people.

\section{References}

Agerbæk M, Gerdes LU \& Richelsen B (1995) Hypocholesterolaemic effect of a new fermented milk product in healthy middle-aged men. European Journal of Clinical Nutrition 49 , 346-352.

Allain CC, Poon LS, Chan CSG, Richmond W \& Fu PC (1974) Enzymatic determination of total serum cholesterol. Clinical Chemistry 20, 470-475.

Aries VC, Crowther JS, Drasar BS, Hill MJ \& Williams REO (1969) Bacteria and the aetiology of cancer of the large bowel. Gut 10, 334-335.

Armstrong B \& Doll R (1975) Environmental factors and cancer incidence and mortality in different countries with special reference to dietary practices. International Journal of Cancer $15,617-631$.

Black DD \& Davidson NO (1989) Intestinal apolipoprotein synthesis and secretion in the suckling pig. Journal of Lipid Research 30, 207-218.

Black DD, Rohwer-Nutter PL \& Davidson NO (1990) Intestinal apo A-IV gene expression in the piglet. Journal of Lipid Research 31, 497-505. 
Chapman MJ (1986) Comparative analysis of mammalian plasma lipoproteins. Methods in Enzymology 128, 70-143.

Chikai T, Nakao H \& Uchida K (1987) Deconjugation of bile acids by human intestinal bacteria implanted in germ-free rats. Lipids 22, 669-671.

Cohen BI, Raicht FR, Deschner EE, Takahashi M, Sarwal AN \& Fazzini E (1980) Effect of cholic acid feeding on N-methyl-Nnitrosourea-induced colon tumors and cell kinetics in rats. Joumal of the National Cancer Institute 64, 573-578.

Costa NMB, Low AG, Walker AF, Owen RW \& Englyst HN (1994) Effect of baked beans (Phaseolus vulgaris) on sterol metabolism and non-starch polysaccharide output of hypercholesterolaemic pigs with or without an ileo-rectal anastomosis. British Journal of Nutrition 71, 871-886.

Danielson AD, Peo ER, Shahani KM, Lewis AJ, Whalen PJ \& Amer MA (1989) Anticholesterolemic property of Lactobacillus acidophilus yogurt fed to mature boars. Journal of Animal Science 67, 966-974.

Dashkevicz MP \& Feighner SD (1989) Development of a differential medium for bile salt hydrolase active Lactobacillus sp. Applied and Environmental Microbiology 55, 11-16.

De Smet I, Van Hoorde L, De Saeyer N, Vande Woestyne M \& Verstraete W (1994) In vitro study of bile salt hydrolase (BSH) activity of BSH isogenic Lactobacillus plantarum 80 strains and estimation of cholesterol lowering through enhanced BSH activity. Microbial Ecology in Health and Disease 7, 315-329.

Dupont J, Oh S-Y, O'Deen L, McClellan MA, Lumb WV \& Butterfield AB (1974) Cholesterol and bile acid turnover in miniature swine. Lipids 9, 717-721.

Fossati P \& Prencipe L (1982) Serum triglycerides determined colorimetrically with an enzyme that produces hydrogen peroxide. Clinical Chemistry 28, 2077-2080.

Friedewald WT, Levy RJ \& Frederickson DS (1972) Estimation of the concentration of low-density-lipoprotein cholesterol in plasma, without use of the preparative centrifuge. Clinical Chemistry 18, 499-502.

Fukushima M \& Nakano M (1995) The effect of a probiotic on faecal and liver lipid classes in rats. British Journal of Nutrition 73, 701-710.

Grundy SM (1972) Treatment of hypercholesterolaemia by interference with bile acid metabolism. Archives of Internal Medicine 130, 638-648.

Grundy SM, Ahrens EH Jr \& Salen G (1972) Interruption of the enterohepatic circulation of bile acids in man: comparative effect of cholestyramine and ileal exclusion on cholesterol metabolism. Journal of Laboratory and Clinical Medicne 78, 94-121.

Gustafsson BE, Gustafsson JA \& Carlstedt-Duke B (1977) Prolonged induction of germ-free bile acid pattern in conventional rats by antibiotics. Acta Medica Scandinavica 201, 155-160.

Hylemon PB \& Glass TL (1983) Biotransformations of bile acids and cholesterol by the intestinal microflora. In Human Intestinal Flora in Health and Disease, pp. 79-99 [DJ Hentges, editor]. New York: Academic Press.

Juste C, Demarne Y \& Corring T (1983) Response of bile flow, biliary lipids and bile acid pool in the pig to quantitative variations in dietary fat. Journal of Nutrition 113, 1691-1701.

Kandell RL \& Bernstein C (1991) Bile salt/acid induction of DNA damage in bacterial and mammalian cells: implications for colon cancer. Nutrition and Cancer 16, 227-238.

Kidder DE \& Manners MJ (1978) Digestion in the Pig. Bath: Kingston Press.

Kim DN, Lee KT, Reiner JM \& Thomas WA (1980) Increased steroid excretion in swine fed high-fat, high-cholesterol diet with soy protein. Experimental and Molecular Pathology 33, 25-35.
Korpela JT, Adlercreutz H \& Turunen MJ (1988) Fecal free and conjugated bile acids and neutral sterols in vegetarians, omnivores and patients with colorectal cancer. Scandinavian Journal of Gastroenterology 23, 277-283.

Lapré JA, de Vries HT, Termont DSML, Kleibeuker JH, de Vries EGE \& van der Meer R (1993) Mechanisms of the protective effect of supplemental dietary calcium on cytolytic activity of fecal water. Cancer Research 53, 248-253.

Madsen DC, Worstmann BJ, Beaver M \& Chang L (1978) Effects of aureomycin on bile acids in rats. Journal of Laboratory and Clinical Medicine 91, 605-611.

Marteau P, Gerhardt MF, Myara A, Bouvier E, Trivin F \& Rambaud JC (1995) Metabolism of bile salts by alimentary bacteria during transit in the human small intestine. Microbial Ecology in Health and Disease 8, 151-157.

Marteau P \& Rambaud JC (1993) Potential of using lactic acid bacteria for therapy and immunomodulation in man. FEMS Microbiology Reviews 12, 207-220.

Mashige F, Tanaka N, Maki A, Kamei S \& Yamanaka M (1981) Direct spectrophotometry of total bile acid in serum. Clinical Chemistry 27, 1352-1356.

Miller ER \& Ulirey DE (1987) The pig as a model for human nutrition. Annual Review of Nutrition 7, 361-365.

Mott GE, Moore RW, Redmond HE \& Reiser R (1973) Lowering of serum cholesterol by intestinal bacteria in cholesterol-fed piglets. Lipids 8, 428-431.

Nagengast FM, Grobben MJ \& van Munster IP (1995) Role of bile acids in colorectal carcinogenesis. European Journal of Cancer 31, 1067-1070.

Owen RW, Henly PJ, Thompson MH \& Hill MJ (1986) Steroids and rancer: faecal bile acid screening for early detection of cancer risk. Journal of Steroid Biochemistry 24, 391-394.

Ratcliffe HL \& Luginbühl H (1971) The domestic pig: a model for experimental atherosclerosis. Atherosclerosis 13, 133136.

Scholz K-E, Kinder E, Hagemeister H \& Barth CA (1985) Influence of dietary casein and soy protein isolate on intestinal cholesterol and bile acid concentration. Zeitschrift für Ernährungswissenschaft 24, 158-171.

Suckling KE, Benson GM, Bond B, Gee A, Glen A, Haynes C \& Jackson B (1991) Cholesterol lowering and bile acid excretion in the hamster with cholestyramine treatment. Atherosclerosis 89, 183-190.

Tannock GW \& McConnell MA (1994) Lactobacilli inhabiting the digestive tract of mice do not influence serum cholesterol concentrations. Microbial Ecology in Health and Disease 7, 331-334.

Tannock GW, Tangerman A, Van Schaik A \& McConnell A (1994) Deconjugation of bile acids by lactobacilli in the mouse small bowel. Applied and Environmental Microbiology 60, 3419-3420.

Taylor EW \& Burman NP (1964) The application of membrane filtration techniques to the bacteriological examination of water. Journal of Applied Bacteriology 27, 297-303.

van Faassen A, Bol J, van Dokkum W, Pikaar NA, Ockhuizen T \& Hermus RJJ (1987) Bile acids, neutral steroids and bacteria in faeces as affected by a mixed, a lacto-ovovegetarian and a vegan diet. American Journal of Clinical Nutrition 46, 962967.

Warnick GR, Benderson J \& Albers JJ (1982) Dextran sulfate- $\mathrm{Mg}^{2+}$ precipitation procedure for quantification of high-density-lipoprotein cholesterol. Clinical Chemistry 28, 1379-1388.

Wolf BW, Garleb KA, Ataya DG \& Casas IA (1995) Safety and tolerance of Lactobacillus reuteri in healthy adult male subjects. Microbial Ecology in Health and Disease 8, 41-50. 